\title{
EXTRATOS DE PIMENTAS (Capsicum spp.) PARA INIBIÇÃO DO CRESCIMENTO MICELIAL IN VITRO DE Rhizoctonia solani Kuhn
}

\author{
José Roberto Vieira Junior ${ }^{1}$, Cléberson de Freitas Fernandes ${ }^{1}$, Rita de Cássia \\ Alves $^{2}$, Aline Souza da Fonseca ${ }^{2}$, Tamiris Chaves Freire ${ }^{3}$ \\ 1 Pesquisador, Doutor da Embrapa Rondônia \\ 2 Mestranda em Ciências Ambientais \\ 3 Mestra em Ciências Ambientais \\ Autor para correspondência: jose-roberto.vieira@embrapa.br, Empresa Brasileira de \\ Pesquisa Agropecuária. Porto Velho - Brasil \\ Recebido em: 08/04/2016 - Aprovado em: 30/05/2016 - Publicado em: 20/06/2016 \\ DOI: 10.18677/Enciclopedia_Biosfera_2016_152
}

\begin{abstract}
Objetivou-se avaliar in vitro a eficiência de diferentes extratos de pimentas sobre o crescimento micelial de Rhizoctonia solani. O delineamento experimental utilizado foi o inteiramente casualizado com 23 tratamentos, composto por 10 extratos aquosos, 10 extratos alcóolicos e três controles (água, álcool e fungicida), com quatro repetições. Os dados foram submetidos à análise de variância e teste de comparação de médias (Tukey) $(\mathrm{p}<0,05)$. Determinou-se o crescimento micelial para avaliar os possíveis efeitos de inibição por meio da determinação do diâmetro. Paralelamente foi conduzido ensaios de compostos voláteis. Dos extratos brutos testados, cinco se mostraram eficientes na inibição do crescimento micelial de $R$. solani: os extratos aquosos de folhas de malagueta mexicana, bojuda, juremá, dedode-moça e pimenta de cheiro. Nos ensaios de diluição, exceto os extratos de juremá $(1 / 1000$ e $1 / 10000)$ e bojuda (1/10000) todos os extratos inibiram o crescimento de $R$. solani. Nos ensaios de compostos voláteis, os extratos de Juremá e malagueta mexicana tiverem efeito fungistático. Esses resultados demonstram a potencialidade do uso de extratos de pimenta no controle de $R$. solani.
\end{abstract}

RESUMO

PALAVRAS-CHAVE: Antibiograma, Controle alternativo, feijão

\section{EXTRACTS PEPPERS (Capsicum spp.) FOR GROWTH IN VITRO INHIBITION MYCELIAL Rhizoctonia solani Kuhn}

\section{ABSTRACT}

The aim was to evaluate in vitro the efficiency of different extracts of peppers on the Mycelial growth of Rhizoctonia solani. The experimental design used was the completely randomized design with 23 treatments, composed of 10 aqueous extracts, 10 alcoholics extracts and three controls (water, alcohol and fungicide), with four replicates. The data were subjected to analysis of variance and means comparison test (Tukey) $(p<0.05)$. Mycelial growth was determined to assess the possible effects of inhibition by determining the diameter. At the same time was conducted tests of volatile compounds. The crude extracts tested, five were efficient in inhibiting mycelial growth of $R$. solani: aqueous extracts of leaves of mexican chilli, 
bojuda, juremá, dedo-de-moça and pimenta de cheiro. Dilution assays, except juremá extracts (1/1000 and 1/10000) and bojuda (1/10000) all extracts inhibited growth of $R$. solani. For volatiles, juremá extracts and mexican chilli has fungistatic effect. These results demonstrate the potential of using extracts of pepper in the control of $R$. solani.

KEYWORDS: Antibiogram, Alternative control, bean

\section{INTRODUÇÃO}

O Brasil é um dos países mais importantes mundialmente em relação à produção agrícola e diversidade de alimentos, principalmente em relação à produção de grãos que vem aumentando consideravelmente no país. Dentre esses grãos, o feijão foi responsável por 3.414,1 mil toneladas na safra de 2014/2015 (CONAB, 2015). E com o predomínio do aumento na produção houve também um crescimento paralelo do uso de agroquímicos (PORTO \& SOARES, 2012).

Outro fator que tem contribuído para o desenvolvimento do setor de agroquímicos se dá pela resistência desenvolvida por fitopatógenos a certas moléculas, tornando-se ineficientes a determinados patógenos (SILVA et al. 2007; BASSO et al., 2015; CARDOSO, et al., 2015). Por outro lado, diante dos diversos problemas ambientais causados pelo uso exarcebado de agroquímicos na agricultura têm-se buscado métodos alternativos como a procura por extratos vegetais eficientes no controle de fungos fitopatogênicos (SCHWAN-ESTRADA et al., 2000).

Dentre as doenças mais impactantes da cultura do feijoeiro, a mela é causada pelo fungo Rhizoctonia solani. Apresenta características de podridão, sendo comum na América Latina, bem como nas demais regiões do mundo, reduzindo a população de plantas e redução da produção, se mostrando como uma doença importante economicamente (BIANCHINI et al., 2005).

Algumas espécies de plantas apresentam uma diversidade de substâncias em sua composição, advindas de metabolismo primário e secundário, tendo estes muitas vezes potencial atividade antimicrobiana (CELOTO et al., 2008; DOMINGUES et al., 2011; AMORIM et al., 2011; BORGES et al., 2013; ARAÚJO et al., 2014). Alguns trabalhos têm demonstrado o efeito do uso de extratos de plantas. Com relação ao fungo Rhizoctonia solani, existem trabalhos sobre o controle in vitro com uso de extratos de Datura metel, Solanum grandiflorum, Ocimum basilicum, Baccharis trimera e Cnicus benedictus (KAGALEA, 2004; LIMA \& FERREIRA NETO, 2014; BERNARDO et al., 2015).

Estudos com plantas do gênero Capsicum demonstram uma grande diversidade de metabólitos secundários, inclusive com ação inseticida e antifúngica (RIBEIRO \& BEDENDO, 1999; LING et al., 2012; GUIMARÃES et al., 2014; VASCONCELOS et al., 2014). Apesar disto, há poucos estudos com Capsicum sobre o controle de fitopatógenos importantes economicamente.

Diante do exposto, objetivou-se avaliar in vitro a eficiência de diferentes extratos de pimentas sobre o crescimento micelial de Rhizoctonia solani.

\section{MATERIAL E MÉTODOS}

Para os ensaios foram utilizadas 10 variedades comerciais de pimenta (Capsicum spp.), pertencentes ao Banco de Germoplasma do Centro Nacional de Pesquisas em Hortaliças da Embrapa - CNPH, sendo estas: Dedo-de-Moça (Capsicum baccatum L.); Biquinho (Capsicum chinense Jacq.); Síria (Capsicum 
baccatum L.); Juremá (Capsicum frutescens L.); Pitanga amarela (Capsicum baccatum L.); Pimenta de cheiro (Capsicum chinense L.); Bojuda (Capsicum frutescens L.); Chifre-de-bode (Capsicum chinense Jacq.); Malagueta curta (Capsicum frutescens L.) e Malagueta Mexicana (Capsicum annuum L.).

As amostras de folhas de pimentas foram lavadas em água corrente, em seguida sanitizadas em água contendo hipoclorito (0,5\%) por 20 minutos, congelados em Freezer -30 ㅇ C até a preparação dos extratos.

Para a obtenção dos extratos, foram pesadas 10 gramas do material congelado em balança digital. Em seguida, estes foram macerados com nitrogênio $\left(\mathrm{N}_{2}\right)$ líquido até que se tornassem um pó homogêneo e fino, logo após foram adicionados $100 \mathrm{ml}$ do extrator. Foram usados como soluções extratoras: água e álcool etílico $96 \%$ G.L. O extrato obtido foi conservado em erlenmeyer tampado e mantido sob agitação em mesa agitadora Kline modelo Q225K a 100 RPM por 24 horas. Após este período esta suspensão foi filtrada em papel de filtro $100 \%$ celulose e posteriormente em gaze, a fim de retirar as partículas sólidas.

Os extratos obtidos foram transferidos para frascos de vidro esterilizados e mantidos em geladeira para maior conservação. Para cada $100 \mathrm{~mL}$ de extrato, adicionaram-se dois $\mathrm{mL}$ do antibiótico de amplo espectro Cloranfenicol (500 ppm). Das 10 variedades de pimenta selecionadas para os ensaios in vitro, foram obtidos 20 extratos brutos (1/10), sendo 10 extratos alcoólicos e 10 extratos aquosos e os controles.

Para os ensaios foi utilizado o meio de cultura BCA (Batata-Cenoura-Ágar), vertido na placa de Petri de nove $\mathrm{cm}$ de diâmetro. Após a solidificação do meio foi adicionado no centro da placa um disco de micélio de um $\mathrm{cm}$ de diâmetro do fungo Rhizoctonia solani. Ao redor das placas, de forma equidistante, perfurações foram feitas com furador de tecidos vegetais de $0,5 \mathrm{~cm}$ de diâmetro por um $\mathrm{cm}$ de profundidade no meio de cultura.

Dentro destes poços foram dispensados $20 \mu$ dos extratos com auxílio de pipeta automática. Em cada placa foram testados cinco tipos de extratos por placa. Em outras placas, as testemunhas, água ou álcool (conforme o tipo de extrato utilizado aquoso ou alcoólico) e o fungicida comercial Azoxistrobina na concentração de $0,6 \mathrm{~g} / \mathrm{l}$ foram testadas. As placas foram mantidas em incubadora tipo B.O.D. em temperatura média de $25^{\circ} \mathrm{C}\left( \pm 1^{\circ} \mathrm{C}\right)$ por 72 horas, num regime de fotoperíodo de 12 horas claro/escuro, onde o acompanhamento do crescimento do fungo foi diário e medido o diâmetro médio dos halos de inibição com paquímetro digital.

Com base nos resultados obtidos, foram selecionados os cinco melhores extratos e, a partir destes foram produzidos extratos diluídos nas proporções de $1 / 100,1 / 1000,1 / 10000$. Nos ensaios de produção de compostos voláteis, objetivou-se determinar se os extratos produzidos seriam capazes de produzir substâncias voláteis tóxicas ao fungo, capazes de inibir ou retardar o seu crescimento. Utilizou-se apenas os cinco melhores isolados em 4 repetições por isolado.

Assim, em Placas de Petri de nove $\mathrm{cm}$ os extratos foram aplicados no centro da placa de Petri, em cavidade obtida por meio de perfuração com furador de tecidos de $0,5 \mathrm{~cm}$ de diâmetro. O meio-suporte utilizado foi o de ágar-água. $\mathrm{Na}$ tampa da placa foi depositada uma camada de meio de cultura BCA. Sobre este também no centro da tampa, um disco de micélio do fungo de $0,5 \mathrm{~cm}$ de diâmetro foi depositado. As partes da placa foram unidas e seladas com parafilme. Mediu-se diariamente o diâmetro médio de crescimento das colônias. 
O delineamento experimental utilizado foi o inteiramente casualizado com 23 tratamentos, composto por 10 extratos aquosos, 10 extratos alcóolicos e três controles (água, álcool e fungicida) e quatro repetições. Os dados foram submetidos à análise de variância e teste de comparação de médias (Tukey) $(p<0,05)$.

\section{RESULTADOS E DISCUSSÃO}

Dos 20 extratos testados (1/10), cinco extratos mostraram-se eficientes na inibição do crescimento de Rhizoctonia solani. Foram eles: extratos aquosos das folhas de malagueta mexicana, dedo-de-moça, bojuda, Juremá e pimenta de cheiro (Figura 1).

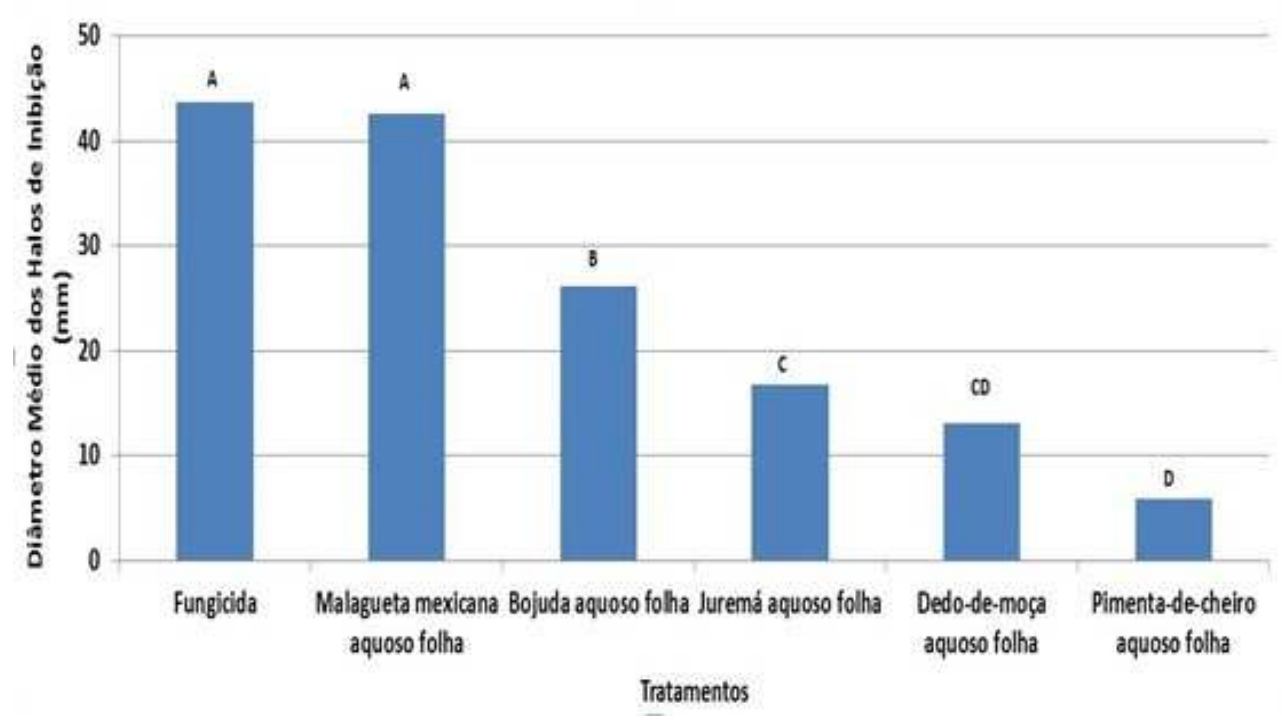

FIGURA 1. Diâmetro médio dos halos de inibição de Rhizoctonia solani. Médias seguidas de mesma letra não diferem entre si pelo teste de Tukey $(p>0,05)$

Os resultados demonstram que o extrato aquoso de pimenta malagueta mexicana apresenta forte inibição do crescimento micelial do fungo, se igualando ao fungicida. Enquanto que pimenta bojuda, pimenta jurema, pimenta dedo-de-moça e pimenta de cheiro apresentaram inibição mediana. Os demais extratos não apresentaram nenhum efeito.

Resultados semelhantes foram obtidos com o uso do extrato aquoso de folhas de Lippia alba (Mill) N. E. Brown. no controle de Colletotrichum gloeosporioides Penz. indicando maior inibição ao crescimento micelial do patógeno com o uso deste (FERREIRA, 2014). Assim como CELOTO et al. (2011), avaliando o efeito dos extratos de Momordica charantia L. na inibição da germinação de conídios e no crescimento micelial de Colletotrichum musae (Berk. \& Curtis) Arx., observaram que o extrato aquoso e o fungicida tiofanato metílico proporcionaram $100 \%$ de inibição da germinação dos conídios, diferindo-se dos demais extratos.

Nos ensaios de inibição com extratos diluídos (1/100), foi possível observar que os mesmos apresentaram níveis de inibição semelhantes entre si, mas diferentes quando comparados com o tratamento com fungicida (Figura 2). 


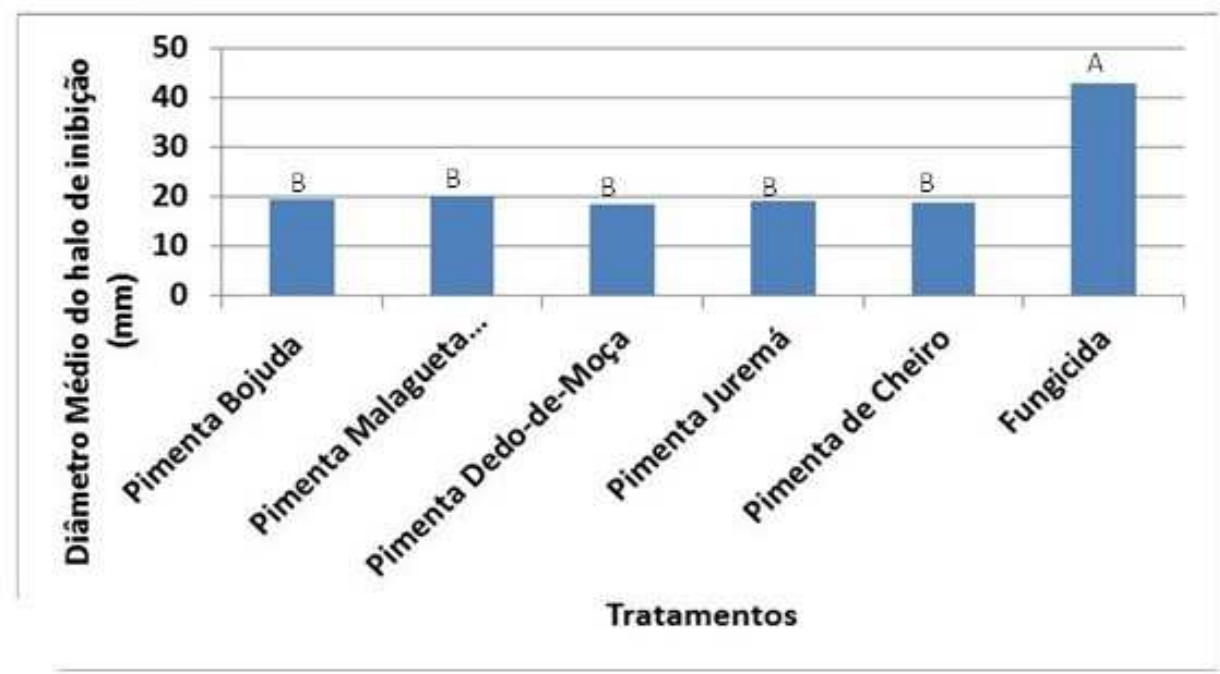

FIGURA 2. Média de inibição do crescimento micelial de $R$. solani contra extratos de pimentas diluídos à 1/100 vezes.

Médias seguidas de mesma letra não diferem entre si pelo teste de Tukey $(p>0,05)$

Nos ensaios de inibição com extratos diluídos (1/1.000), foi possível observar que o extrato de pimenta jurema não alterou o crescimento micelial do fungo $R$. solani. Assim como os extratos diluídos (1/10.000), de pimenta jurema e pimenta bojuda.

As maiores concentrações de extratos de Ruta graveolens L., Mentha $\mathrm{x}$ villosa, Calendula officinalis L., Momordica charantia L., Symphytum officinale L., Ageratum conyzoides $\mathrm{L}$. e Ricinus comunis $\mathrm{L}$. resultaram em maiores porcentagens de inibição, próximas de 100\%, 30\%, 35\% e 40\%, respectivamente, a $10000 \mathrm{mg} \mathrm{L}-1$ sobre a inibição do crescimento micelial de Cercospora calendulae Sacc. (NASCIMENTO et al., 2013).

Em ensaios de fungitoxicidade BRITO \& NASCIMENTO (2015) testando o efeito de extratos de alho, citronela, gengibre e nim em diferentes concentrações (5, $15,25,35$, e $45 \%$ ) no controle in vitro de Curvularia eragrostidis, observaram que a utilização de todos os extratos a partir da concentração de $25 \%$ apresentaram maiores efeitos fungitóxico, reduzindo o crescimento micelial, a esporulação, e germinação do patógeno.

Nos ensaios de compostos voláteis foi determinada a produção de compostos voláteis. Neste, pode-se observar que o extrato de pimenta bojuda obteve a maior eficiência em retardar o crescimento do fungo, com uma média de $79,9 \mathrm{~mm}$, não permitindo o crescimento em toda a placa $(90 \mathrm{~mm}$ ) (Figura 3), mostrando que existem compostos orgânicos voláteis existentes nesta espécie, com possível efeito fungistático. 


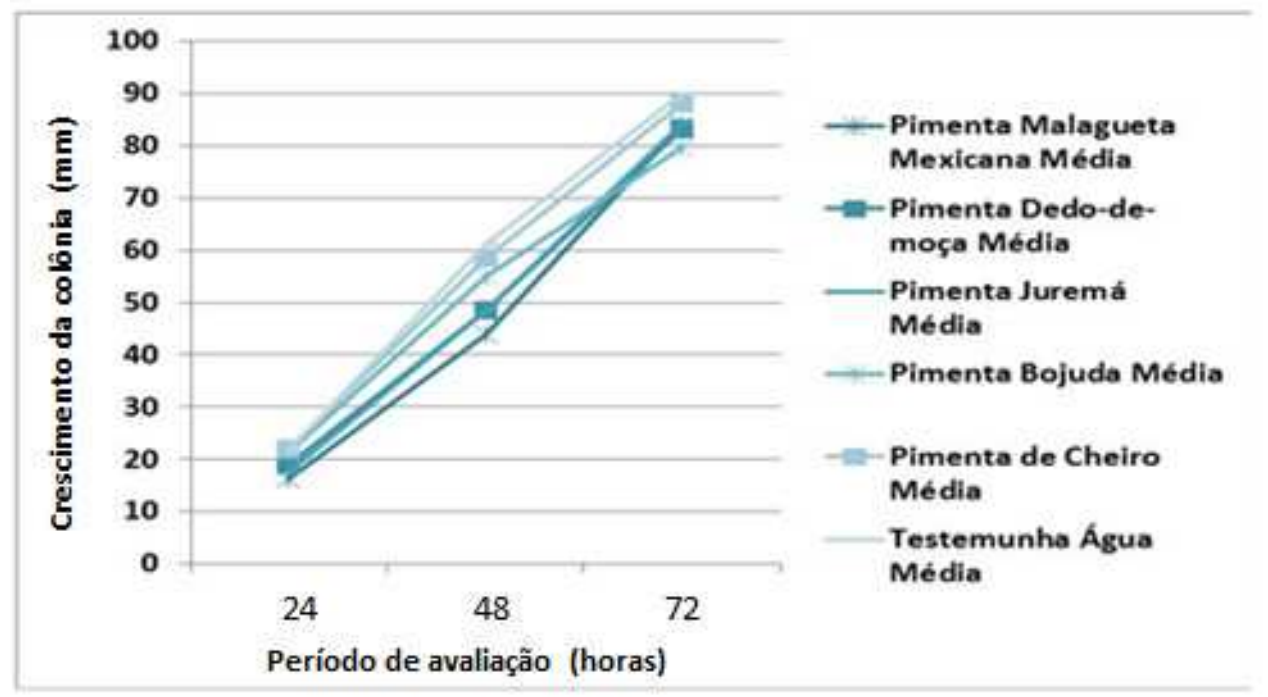

FIGURA 3. Curva de crescimento micelial de $R$. solani em ensaios de produção de compostos voláteis por extratos de pimentas.

SOUSA et al. (2006), avaliando os perfis de compostos voláteis que contribuem para o aroma de variedades vermelhas, amarelas e roxas de Capsicum chinense sp. encontraram compostos orgânicos voláteis como, éster de hexilo do ácido pentanóico, dimethylcyclohexanols, humuleno e ésteres de ácido butanóico.

Os resultados obtidos em relação à área abaixo da curva do progresso da doença demonstram que os extratos obtiveram uma ação fungistática e não fungicida, apenas retardando o crescimento micelial do patógeno. Obteve-se os melhores resultados com as pimentas malagueta mexicana e Juremá (Figura 4).

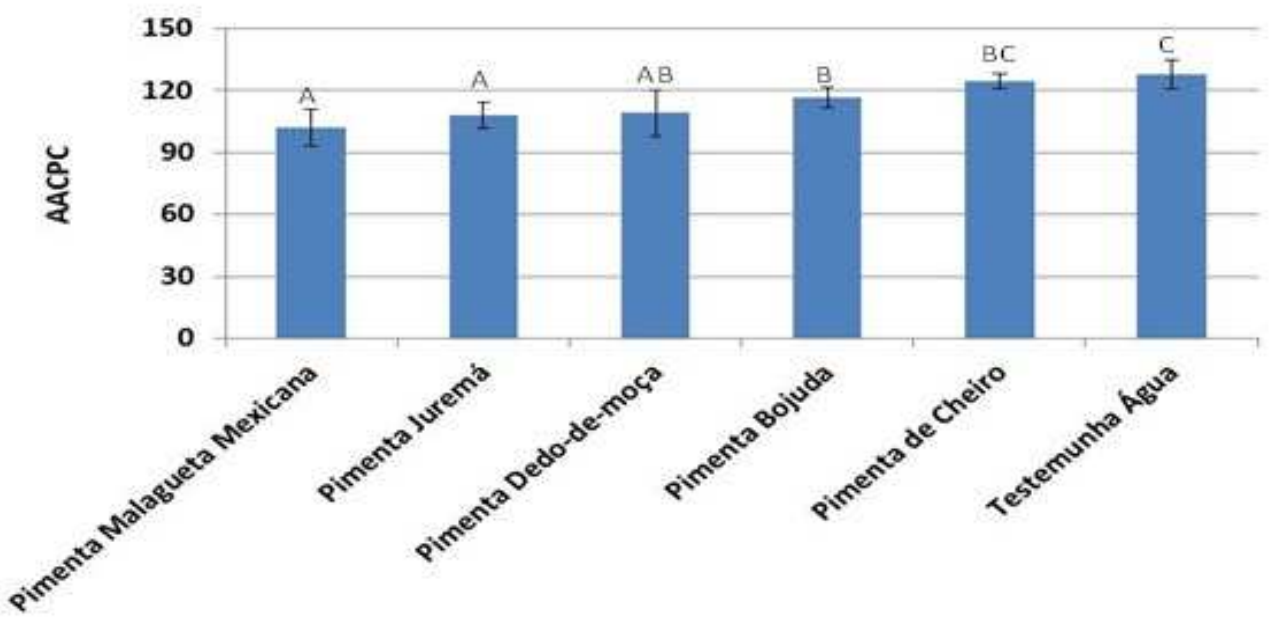

FIGURA 4. Área abaixo da curva do progresso de crescimento de $R$. solani in vitro em função do extrato testado.

Médias seguidas de mesma letra não diferem entre si pelo teste de Tukey $(p>0,05)$ 
SEIXAS et al. (2011), ao avaliarem o efeito fungitóxico do óleo essencial de capim-citronela e do citronelal sobre a inibição micelial do fitopatógeno Fusarium subglutinans, observaram que o óleo essencial do capim-citronela demonstrou maior efeito inibitório do crescimento micelial do fungo $F$. subglutinans do que o composto citronelal, demonstrando assim, um efeito fungistático sobre o patógeno. Outro fator observado foi a diminuição da eficiência dos extratos brutos após 90 dias conservados em geladeira, onde os mesmos apresentaram médias de inibição não tão satisfatórias quando usados dias após o seu preparo.

Estudos revelam que as características do pimentão em pó acondicionado em embalagem de polietileno durante 100 dias de armazenamento em temperatura ambiente sofrem alterações das características ao longo do armazenamento (ARLINDO et al., 2007). Resultados semelhantes foram obtidos por SOUSA et al. (2008), que relatam que o armazenamento do extrato em geladeira também teve depreciou a ação acaricida e larvicida do extrato.

A eficiência dos extratos aquosos e a ineficiência dos extratos alcoólicos podem ter sido influenciados devido os flavonóides. Estas substâncias são mais facilmente extraídas em meios polares como o etanol enquanto os ácidos e os açúcares pelos extratos aquosos (EDWARDS et al., 2012).

\section{CONCLUSÃO}

Os extratos de folhas de pimentas possuem efeito de inibição de crescimento micelial sobre o fungo $R$. solani e a medida que é aumentado a concentração dos extratos a atividade antifúngica aumenta.

\section{REFERÊNCIAS}

AMORIM, E. P. R.; ANDRADE, F. W. R.; MORAES, E. M. S.; SILVA, J. C.; LIMA, R. S.; LEMOS, E. E. P. Atividade antibacteriana de óleos essenciais e extratos vegetais sobre o desenvolvimento de Ralstonia solanacearum em mudas de bananeira. Revista Brasileira de Fruticultura, v. E, p. 392-398, 2011. Disponível em:< http://dx.doi.org/10.1590/S0100-29452011000500050>. doi: 10.1590/S010029452011000500050

ARAÚJO, E.R.; HARAND, W.; LIMA, I.C.; DIAS, F. C. R. I.; SANTANA, A. A. D.; COSTA, R. R. C.; LARANJEIRA, D. Extratos de Piper marginatum e Azadirachta indica no controle de Colletotrichum scovillei em pimentão. Pesquisa Agropecuária Brasileira, v. 49, n. 2, p. 88-94, 2014. Disponível em: <http://dx.doi.org/ 10.1590/S0100-204X2014000200002>. doi: 10.1590/S0100-204X2014000200002

ARLINDO, D. M.; QUEIROZ , A. J. M.; FIGUEIREDO, R. M. F. Armazenamento de pimentão em pó em embalagem de polietileno. Revista Brasileira de Produtos Agroindustriais, v.9, n.2, p.111-118, 2007. Disponível em: < http://dx.doi.org/10.15871/1517-8595/rbpa.v9n2p111-118>. doi: 10.15871/15178595/rbpa.v9n2p111-118

BASSO, P.; BONALDO, S. M.; RUFFATO, S. Avaliação de fungicidas no controle de antracnose e mancha alvo, e no rendimento da cultura da soja. Scientia Agraria Paranaensis, v. 14, n. 3, p. 191-199, $2015 . \quad$ Disponível em: <http://dx.doi.org/10.18188/1983-1471/sap.v14n3p191-199> . doi: 10.18188/19831471/sap.v14n3p191-199 
BERNARDO, R.; SCHWAN-ESTRADA, K. R. F.; STANGARLIN, J. R.; OLIVEIRA, J. S. B.; CRUZ, M. E. S.; MESQUINI, R. M. Atividade fungitóxica in vitro de extratos vegetais sobre o crescimento micelial de fungos fitopatogênicos. Scientia Agraria Paranaensis, v. 14, n. 2, p. 89-93, 2015. Disponível em:< http://dx.doi.org/10.18188/1983-1471/sap.v14n2p89-93>. doi: 10.18188/19831471/sap.v14n2p89-93

BIANCHINI. A. A. C. MARINGONI E S. M. T. P. G. CARNEIRO. 2005. Doenças do feijoeiro (Phaseolus vulgaris). In: KIMATI. H.. L. AMORIM. J. A. M. REZENDE. A. BERGAMIN FILHO e L. E. A. CAMARGO. Vol. 2. (4 Ed.). Manual de Fitopatologia. Agronômica Ceres. São Paulo.

BRITO, N. M.; NASCIMENTO, L. C. Potencial fungitóxico de extratos vegetais sobre Curvularia eragrostidis (P. Henn.) Meyer in vitro. Revista brasileira de plantas medicinais, v.17, n. 2, p.230-238, 2015. Disponível em: <http://dx.doi.org/10.1590/1983-084X/10_057>.doi: 10.1590/1983-084X/10_057

BORGES, D. I.; ALVES, E.; MORAES, M. B.; OLIVEIRA, D. F. Efeito de extratos e óleos essenciais de plantas na germinação de urediniósporos de Phakopsora pachyrhizi. Revista Brasileira de Plantas Medicinais, v.15, n.3, p.325-331, 2013. Disponível em: <http://dx.doi.org/10.1590/S1516-05722013000300003>. doi: 10.1590/S1516-05722013000300003

CARDOSO, S. S.; LOPES, M. C.; SILVA JÚNIOR, J. F.; BORGE, B. M. M. N. Eficiência de fungicidas no controle do mofo branco na cultura da soja. Scientia Agraria Paranaensis, v. 14, n. 1, p. 49-52, 2015. Disponível em: <http://dx.doi.org/10.18188/1983-1471/sap.v14n1p49-52>. doi: 10.18188/19831471/sap.v14n1p49-52

CELOTO, M. I. B.; PAPA, M. F. S.; SACRAMENTO, L. V. S.; CELOTO, F. J. Atividade antifúngica de extratos de plantas a Colletotrichum gloeosporioides. Acta Scientiarum Agronomy, v. 30, n. 1, p. 1-5, 2008. Disponível em: <http://dx.doi.org/10.4025/actasciagron.v30i1>. doi: 10.4025/actasciagron.v30i1

CELOTO, M. I. B.; PAPA, M. F. S.; SACRAMENTO, L. V. S.; CELOTO, F. J. Atividade antifúngica de extratos de Momordica charantia L. sobre Colletotrichum musae. Revista brasileira de plantas medicinais, v. 13, n. 3, p. 337-341, 2011. Disponível em: <http://dx.doi.org/10.1590/S1516-05722011000300013>. doi: 10.1590/S1516-05722011000300013

CONAB. Acompanhamento da Safra Brasileira - Grãos, v. 2 - Safra 2014/15, n. 9 - Nono levantamento, junho 2015, disponível em: http://www.conab.gov.br Acesso em 17 de junho de 2015. 
DOMINGUES, R. J.; YOUNG, M. C. M.; TÖFOLI, J. G.; MATHEUS, D. R. Potencial antifúngico de extratos de plantas e de basidiomicetos nativos sobre Colletotrichum acutatum, Alternaria solani e Sclerotium rolfsii. Summa phytopathologica, v. $37 \mathrm{n}$. 3 , p. 149-151, 2011. Disponível em: <http://dx.doi.org/10.1590/S010054052011000300013>. doi: 10.1590/S0100-54052011000300013

EDWARDS, J. E.; BROWN, P. N. TALENT, N.; DICKINSON, T. A.; SHIPLEY, P. R. A review of the chemistry of the genus Crataegus. Phytochemistry, v. 79, p. 5-26, 2012. Disponível em: <http://dx.doi.org/10.1016/j.phytochem.2012.04.006>. doi: 10.1016/j.phytochem.2012.04.006.

FERREIRA, E. F.; SÃO JOSÉ, A. R.; BOMFIM, M. P.; PORTO, J. S.; JESUS, J. S. Uso de extratos vegetais no controle in vitro do Colletotrichum gloeosporioides Penz. coletado em frutos de mamoeiro (Carica papaya L.). Revista Brasileira de Fruticultura, v. 36, n. 2, p. 346-352, 2014 . Disponível em:< http://dx.doi.org/10.1590/0100-2945-223/13>. doi: 10.1590/0100-2945-223/13

GUIMARÃES, S. S.; POTRICH, M.; SILVA, E. R. L.; WOLF, J.; PEGORINI C. S.; OLIVEIRA, T. M. Ação repelente, inseticida e fagoinibidora de extratos de pimenta dedo-de-moça sobre o gorgulho do milho. Agricultural Entomology, v. 81, n. 4, p. 322-328, 2014. Disponível em:<http://dx.doi.org/10.1590/1808-1657000172013>. doi: $10.1590 / 1808-1657000172013$

KAGALEA, S.; MARIMUTHUA, T.; THAYUMANAVANB, B.; NANDAKUMARA, R., SAMIYAPPAN, R. Antimicrobial activity and induction of systemic resistance in rice by leaf extract of Datura metel against Rhizoctonia solani and Xanthomonas oryzae pv. Oryzae. Physiological and Molecular Plant Pathology, v. 65, p. 91-100, 2004. Disponível em:<http://dx.doi.org/10.1016/j.pmpp.2004.11.008>. doi:10.1016/j.pmpp.2004.11.008

LIMA, R. A.; FERREIRA NETO, M. Atividade antifúngica do extrato etanólico dos frutos de Solanum grandiflorum sobre Rhizoctonia solani in vitro. Revista Saúde e Pesquisa, v. $7, \quad$ n. 1, p. 103-108, 2014. Disponível em: <http://dx.doi.org/10.17765/1983-1870.2014v7n1p\%25p>. doi: 10.17765/1983$1870.2014 \mathrm{v} 7 \mathrm{n} 1 \mathrm{p} \% 25 \mathrm{p}$

LING, F.; WANG, J. G.; LU, C.; WANG, G. X.; LUI, Y. H.; GONG, X. N. Effects of aqueous extract of Capsicum frutescens (Solanaceae) against the fish ectoparasite Ichthyophthirius multifiliis. Parasitology Research, v. 111, p. 841-848, 2012. Disponível em:<_http://dx.doi.org/10.1007/s00436-012-2907-9>. 10.1007/s00436012-2907-9

NASCIMENTO, J. M.; SERRA, A. P.; BACCHI, L. M.; GAVASSONI, W. L.; VIEIRA, M. C. Inibição do crescimento micelial de Cercospora calendulae Sacc. por extratos de plantas medicinais. Revista Brasileira de Plantas Medicinais, v.15, n.4, p.751756, 2013. Disponível em: <http://dx.doi.org/10.1590/s1516-05722013000500016>. doi: $10.1590 / s 1516-05722013000500016$

PORTO, M. F.; SOARES, W. L. Modelo de desenvolvimento, agrotóxicos e saúde: um panorama da realidade agrícola brasileira e propostas para uma agenda de 
pesquisa inovadora. Revista Brasileira de Saúde Ocupacional, v. 37, n. 125, p. 17-50, 2012. Disponível em: <http://dx.doi.org/10.1590/S030376572012000100004>. doi: 10.1590/S0303-76572012000100004

RIBEIRO, L. F.; BEDENDO, I. P. Efeito inibitório de extratos vegetais sobre Colletotrichum gloeosporioides - agente causal da podridão de frutos de mamoeiro. Scientia Agrícola, v. 56, n. 4, p. 1267-1271, 1999. Disponível em: <http://dx.doi.org/10.1590/S0103-90161999000500031>. doi: 10.1590/S010390161999000500031

SEIXAS, P. T. L.; CASTRO, H. C.; SANTOS, G. R.; CARDOSO, D. P. Controle fitopatológico do Fusarium subglutinans pelo óleo essencial do capim-citronela (Cymbopogon nardus L.) e do composto citronelal. Revista Brasileira de Plantas Medicinais, v.13 n. E, p. 523-526, 2011. Disponível em: <http://dx.doi.org/10.1590/S1516-05722011000500003>. doi: 10.1590/S151605722011000500003

SOUSA, E. T.; RODRIGUES, F. M.; MARTINS, C. C.; OLIVEIRA, F. S.; PEREIRA, P. A. P.; PEREIRA, J. B. A. Multivariate optimization and HS-SPME/GC-MS analysis of VOCs in red, yellow and purple varieties of Capsicum chinense sp. peppers. Microchemical Journal, v. 82, p. 142-149, 2006. Disponível em: <http://dx.doi.org/10.1016/j.microc.2006.01.017>. doi: 10.1016/j.microc.2006.01.017

SCHWAN-ESTRADA, K. R. F.; STANGARLIN, J. R.; CRUZ, M. E. S. Uso de extratos vegetais no controle de fungos fitopatogênicos. Floresta, v. 30 n. 2, p. 129-137, 2000. Disponível em: <http://dx.doi.org/10.5380/rf.v30i12.2361>. doi: 10.5380/rf.v30i12.2361

SILVA, V. A. S.; JULIATTI, F. C.; SILVA, L. A. S. Interação entre resistência genética parcial e fungicidas no controle da ferrugem asiática da soja. Pesquisa Agropecuária Brasileira, v. 42, n. 9, p. 1261-1268, 2007. Disponível em: <http://dx.doi.org/10.1590/S0100-204X2007000900007>. doi: 10.1590/S0100204X2007000900007

VASCONCELOS, V. O.; MARTINS, M. A. D.; OLIVEIRA, N. J. F.; DUARTE, E. R. Effect of ethanolic extract of Capsicum frutescens $L$. on adult female of Rhipicephalus microplus (Ixodidae). Parasitology Research, v. 113, p. 1389-1394, 2014. Disponível em:<http://dx.doi.org/10.1007/s00436-014-3779-y>. doi: 10.1007/s00436-014-3779-y 